FAKTOR RISIKO KEJADIAN STUNTING PADA BALITA USIA 12-59 BULAN DI WILAYAH TAMBANG POBOYA, KOTA PALU

\title{
Risk Factors Stunting Events At Toddlers Age of 12-59 Months in Poboya Mine Area, City of Palu
}

\author{
Resti Agustia*1, Nurdin Rahman ${ }^{1}$, Hermiyanty ${ }^{2}$ \\ ${ }^{1 .}$ Bagian Gizi Kesehatan Masyarakat, Fakultas Kesehatan Masyarakat, Universitas Tadulako, Indonesia \\ 2. Program Studi Kesehatan Masyarakat, Fakultas Kesehatan Masyarakat, Universitas Tadulako, Indonesia
}

Diterima: 24 November 2018; Revisi: 06 Desember 2018; Diterbitkan: 31 Desember 2018

\section{Abstract}

Background \& Objective: Stunting is a malnutrition that illustrates stunted growth, which is long and takes time to recover. Poboya gold mining is the largest source of entry of mercury metals, the danger posed that affects the growth. This study aims to determine the risk factors of exclusive breastfeeding, infectious diseases and immunization status with the incidence of stunting in children aged 12-59 months in the Poboya Mine Region . Material and Methods: This type of research is quantitative with case control method. The number of samples used in this study were 84 respondents consisting of 21 cases and 63 controls with a ratio of 1: 3. Sampling using total sampling technique. Exclusive breastfeeding data, infectious diseases and immunization status were obtained through interviews using questionnaires. Data analysis used univariate and bivariate analysis. Data obtained from statistical analysis using Odds ratio (OR). Results: Toddlers who get exclusive breastfeeding are $28.6 \%$ (case group) and $65.1 \%$ (control group). Toddlers who suffer from infectious diseases are $81.0 \%$ (case group) and $55.6 \%$ (control group). The immunization status incomplete $52.4 \%$ (case group) and $22.2 \%$ (control group). The toddlers were not exclusively breastfed OR $=4,659(95 \%$ CI $1,583-13,708)$, history of infectious disease OR $=3,400(95 \%$ CI $1.027-11,257)$ and immunization status OR $=$ 3,850 (95\% CI 1,358-10,916) stunting event. Conclusion: The conclusions of this study are non-exclusive breastfeeding, history of infectious diseases and incomplete immunization is a risk factor for stunting. .

Keywords: Stunting, Exclusive Breastfeeding, Infectious Diseases, Immunization, Toddler

\section{Abstrak}

Latar Belakang \& Tujuan : Stunting merupakan keadaan kurang gizi yang menggambarkan terhambatnya pertumbuhan, yang sudah berjalan lama dan memerlukan waktu untuk pulih kembali. Pertambangan emas Poboya merupakan sumber terbesar masuknya logam merkuri, bahaya yang ditimbulkan yaitu berpengaruh terhadap pertumbuhan. Penelitian ini bertujuan untuk mengetahui faktor risiko ASI eksklusif, penyakit infeksi dan status imunisasi dengan kejadian stunting pada balita usia 12-59 bulan di Wilayah Tambang Poboya. Bahan dan Metode : Jenis penelitian ini adalah kuantitatif dengan metode case control. Jumlah sampel yang digunakan dalam penelitian ini adalah 84 responden yang terdiri dari 21 kasus dan 63 kontrol dengan perbandingan 1:3. Pengambilan sampel menggunakan teknik total sampling. Data ASI eksklusif, penyakit infeksi dan status imunisasi diperoleh melalui wawancara menggunakan kuisioner. Analisis data menggunakan analisis univariat dan bivariat. Data yang diperoleh dari analisis statistik dengan menggunakan uji Odds ratio (OR) Hasil : Balita yang mendapatkan ASI Eksklusif yaitu 28,6\% (kelompok kasus) dan $65,1 \%$ (kelompok kontrol). Balita yang mendeirta penyakit infeksi yaitu $81,0 \%$ (kelompok kasus) dan 55,6\% (kelompok kontrol). Adapun status imunisasi yang tidak lengkap yaitu 52,4\% (kelompok kasus) dan 22,2\% (kelompok kontrol). Balita tidak ASI eksklusif OR = 4,659 (CI 95\% 1,583-13,708), riwayat penyakit infeksi OR = 3,400 (CI 95\% 1,027-11,257) dan status imunisasi OR $=3,850$ (CI 95\% 1,358-10,916) merupakan faktor risiko kejadian stunting Kesimpulan : Pemberian ASI tidak eksklusif, riwayat penyakit infeksi dan imunisasi tidak lengkap merupakan faktor risiko stunting .

Kata Kunci: Stunting, ASI, Penyakit Infeksi, Imunisasi, balita

*Korespondensi: Email : reski_kesmasb@yahoo.com

\section{PENDAHULUAN}

Stunting (tubuh pendek) adalah keadaan tubuh yang sangat pendek hingga melampaui defisit 2 SD di bawah median panjang atau tinggi badan populasi yang menjadi referensi internasional. Balita usia 12-59 bulan merupakan usia yang rentan terhadap masalah gizi terutama stunting. 
Sejumlah penelitian memperlihatkan keterkaitan antara stunting dengan perkembangan motorik dan mental yang buruk pada usia kanak-kanak dini, serta prestasi kognitif dan prestasi sekolah yang buruk pada usia kanak-kanak lanjut (Gibney, 2008).

Prevalensi stunting dibeberapa Negara di Afrika, Asia, Amerika Selatan dan Amerika Tengah dan Kaniba berkisar antara $30-50 \%$. Prevalensi stunting pada anak-anak berusia $<5$ tahun di Guatemala mengalami peningkatan di tahun 1998 prevalensi stunting 53,1\% dan pada tahun 2002 menjadi 54,3\%. Begitu juga dengan Haiti mengalami peningkatan dari tahun 2000 prevalensi stunting 28,3\% menjadi $29,7 \%$ pada tahun 2006, dan Peru terjadi penurunan di tahun 1996 yaitu $31,6 \%$, prevalensi stunting di Peru masih berada dikisaran $30 \%$ pada tahun 2005, sedangkan prevalensi stunting di Asia tahun 2007 adalah 30,6\% (UNSCN, 2008).

Menurut data Riskesdas 2013 Prevalensi stunting secara nasional pada tahun 2013 adalah 37,2\%. Hal ini terjadi peningkatan dibandingkan tahun $2010(35,6 \%)$ dan 2007 (36,8\%). Prevalensi stunting sebesar 37,2\% terdiri dari 18,0\% sangat pendek dan 19,2\% pendek (Kementerian Kesehatan RI, 2013). Di Sulawesi Tengah pada tahun 2015 balita sangat pendek adalah 11.4 $\%$ dan balita pendek adalah $23.9 \%$. Sedangkan untuk Kota Palu prevalensi stunting pada balita adalah 36\% (Dinas Kesehatan Provinsi Sulawesi Tengah, 2015).

Penelitian ini bertujuan untuk menganalisis faktor risiko yang berhubungan dengan kejadian stunting pada balita di daerah tambang emas Poboya Kota Palu

\section{BAHAN DAN METODE}

\subsection{Jenis Penelitian}

Jenis penelitian menggunakan Survey Analitik dengan pendekatan Case Control

\subsection{Sampel Penelitian}

Jumlah sampel yaitu sebanyak 84 responden dengan perbandingan 1:3. Pengambilan sampel menggunakan teknik total sampling.

\subsection{Pengumpulan Data}

Pengumpulan data melalui observasi langsung, wawancara, kuesioner dan data dari instansi terkait. Data stunting diperoleh melalui pengukuran tinggi badan anak menggunakan meteran (mikrotoise) dan umur anak, kemudian di analisis dengan menggunakan program WHO Antro. Riwayat pemberian ASI Eksklusif dan Penyakit infeksi serta status imunisasi yaitu dengan melakukan wawancara langsung kepada ibu balita

\subsection{Analisis Data}

Analisis penelitian menggunakan uji odd ratio dengan tingkat kemaknaan 5\% dan derajat kepercayaan (CI) $95 \%$.

\section{HASIL}

Hasil analisis Odds Ratio (OR) dengan Confidence Interval (CI) 95\% menunjukkan adanya risiko ASI tidak eksklusif terhadap kejadian stunting OR $=4,659$ $(1,583-13,708)$, riwayat penyakit infeksi terhadap kejadian stunting OR = 3,400 $(1,027-11,257)$ dan status imunisasi terhadap kejadian stunting $\mathrm{OR}=3,850$ $(1,358-10,916)$

\section{PEMBAHASAN ASI Eksklusif}

ASI Eksklusif adalah pemberian ASI saja kepada bayi sejak usia 0-6 bulan, tanpa penambahan apapun, walaupun itu hanya air dan benar-benar hanya ASI. Hal ini disebabkan ukuran lambung bayi masih sangat kecil dan dengan ASI saja sudah memenuhi seluruh kebutuhan gizi bayi secara sempurna. Pada bayi, ASI sangat berperan dalam pemenuhan gizinya. Konsumsi ASI juga meningkatkan kekebalan tubuh bayi sehingga menurunkan risiko penyakit infeksi. Sampai usia 6 bulan, bayi direkomendasikan hanya mengonsumsi Air Susu Ibu (ASI) eksklusif (Kementerian Kesehatan RI, 2016).

Hasil dalam penelitian ini menunjukkan bahwa ASI eksklusif merupakan faktor risiko terhadap kejadian stunting. Berdasarkan hasil uji statistik, diperoleh OR yaitu 4,659. Hal ini menunjukkan bahwa balita yang tidak diberikan ASI eksklusif berisiko 4,659 kali lebih besar menderita stunting dibandingkan dengan balita yang diberikan ASI eksklusif.

Hal ini sejalan dengan penelitian Rajan dkk (2012) yang menyatakan bahwa anak yang tidak diberikan ASI eksklusif berisiko 6,90 kali (95\% CI 2,81-16,97) lebih besar untuk menderita stunting (Rajan, 2012). Selain itu penelitian Fikadu et al. (2014) menyatakan bahwa anak yang tidak mendapatkan ASI eksklusif $<6$ bulan berisiko 3,27 kali $(95 \%$ CI 1,21-8,82) lebih besar untuk menderita stunting dibandingkan dengan balita yang mendapatkan ASI eksklusif selama 6 bulan pertama. Hasil penelitian yang tidak sejalan ditemukan pada penelitian yang dilakukan oleh Anshori (2013) yang menyatakan bahwa riwayat ASI eksklusif bukan merupakan faktor risiko kejadian stunting dengan OR $=0,375$ (CI 95\% 0,129-1,902).

\section{Riwayat Penyakit Infeksi}

Penyakit infeksi merupakan salah satu penyebab langsung terjadinya masalah gizi, khususnya stunting. Infeksi sering terjadi bersamaan dengan malnutrisi. Infeksi yang menyebabkan malnutrisi ini terjadi karena saat seseorang sakit membutuhkan gizi yang lebih untuk melawan penyakitnya ditambah seringkali merasa tidak nafsu makan sehingga asupan gizi tidak adekuat, hal ini semakin mengarahkan kondisi malnutrisi pada infeksi. Semakin sering terjadinya penyakit infeksi pada balita akan cenderung mengalami masalah gizi, karena energi yang dibutuhkan untuk pertumbuhan dialihkan untuk perlawanan tubuh menghadap infeksi (Darmadi, 2008).

Hasil dalam penelitian ini menunjukkan bahwa riwayat penyakit infeksi merupakan faktor risiko stunting. Berdasarkan uji statistik, diperoleh OR yaitu 3,400 . Hal ini menunjukkan bahwa balita yang menderita penyakit infeksi berisiko 3,400 kali lebih besar mengalami stunting dibandingkan dengan balita yang tidak menderita penyakit infeksi.

Penelitian ini sejalan dengan penelitian Picauly \& Toy (2013) yang menyatakan bahwa balita yang menderita penyakit infeksi 10,298 kali $(95 \%$ CI 1,388 76,398) lebih beresiko untuk menderita stunting.

Penelitian ini juga sejalan dengan penelitian yang dilakukan di Uganda oleh Stewart et al. (2013) yang menyatakan anak yang menderita penyakit infeksi mengalami gangguan dalam tumbuh kembangnya. Anak yang menderita diare memiliki nafsu makan yang menurun sehingga asupan zat gizi cenderung menurun. Tingginya kejadian diare disertai gangguan penyerapan dan tingkat kehilangan zat gizi secara berulang-ulang pada anak menyebabkan terganggunya 
proses pertumbuhan. Balita stunting dengan prevalensi diare yang tinggi memiliki tingkat daya imun yang lebih rendah, sehingga jika terpapar dengan polusi udara atau mengonsumsi makanan/minuman yang memicu dapat menimbulkan penyakit ISPA, seperti batuk dan pilek.

Hasil penelitian yang tidak sejalan ditemukan pada penelitian Wahdah et al. (2014) yang menyatakan bahwa penyakit infeksi bukan merupakan faktor risiko stunting. Walaupun penyakit infeksi bisa menjadi penyebab langsung terhadap stunting, kondisi tersebut bisa dipengaruhi oleh faktor penyebab tidak langsung, seperti sosial ekonomi keluarga.

\section{Status Imunisasi}

Imunisasi adalah upaya untuk menimbulkan dan meningkatkan kekebalan terhadap penyakit pada bayi, dilakukan dengan suntikan. Imunisasi harus diberikan kepada bayi dan anak usia sekolah dasar/sederajat. Akan beresiko terjadi wabah seperti penyakit campak jika bayi tidak diimunisasi (Kementerian Kesehatan RI, 2015a). Tidak lengkapnya imunisasi menyebabkan imunitas balita menjadi lemah, sehingga muda untuk terserang infeksi. Anak yang mengalami infeksi jika dibiarkan maka dapat berisiko menjadi stunting (Damanik, 2014).

Hasil dalam penelitian ini menunjukkan bahwa imunisasi merupakan faktor risiko terhadap kejadian stunting. Berdasarkan uji statistik, diperoleh OR yaitu 3,850 .

Hal ini menunjukkan bahwa balita yang tidak mendapatkan imunisasi dasar lengkap berisiko 3,850 kali lebih besar untuk menderita stunting dibandingkan dengan balita yang mendapatkan imunisasi dasar lengkap.

Hal ini sejalan dengan penelitian Swathma dkk (2016) yang menyatakan bahwa anak yang tidak mendapatkan imunisasi dasar lengkap berisiko 2,979 kali $(95 \%$ CI 1,372-11,839) lebih besar untuk menderita stunting. Selain itu, penelitian Susanti dkk (2015) yang menyatakan bahwa status imunisasi meru- pakan faktor risiko kejadian stunting. Anak yang tidak mendapatkan imunisasi lengkap berisiko 3,462 kali (95\% CI 1,427-8,397) lebih besar untuk menderita stunting. Hasil penelitian yang tidak sejalan ditemukan pada penelitian Bentian (2015) menyatakan bahwa pemberian imunisasi bukan merupakan faktor risiko kejadian stunting dengan OR 0,457 (CI 95\% 0,1491396).

\section{E. KESIMPULAN}

Pemberian ASI tidak eksklusif, riwayat penyakit infeksi dan status imunisasi tidak lengkap merupakan faktor risiko kejadian stunting. Saran yang dapat diberikan pada penelitian ini yaitu sebaiknya pihak tenaga kesehatan yang berada di wilayah Poboya melakukan kerja sama dengan para kader untuk memberikan pemahaman kepada masyarakat yang mempunyai balita agar selalu membawa balita ke posyandu untuk diberikan imunisasi agar balita tidak terkena penyakit infeksi yang dapat mengganggu pertumbuhan balita

\section{F. DAFTAR PUSTAKA}

Anshori, A., 2013. Faktor Risiko Kejadian Stunting Pada Anak Usia 12-24 bulan (Studi Di Kecamatan Semarang Timur). Journal Of Nutrition College, 2(4). https://ejournal3.undip.ac.id/index.php/ jnc/article/view/3830

Bentian I, Mayulu N, Rattu A J, M. 2015. Faktor Risiko Terjadinya Stunting pada Anak TK Di Wilayah Kerja Puskesmas Siloam Tamako Kabupaten Kepulauan Sangihe Provinsi Sulawesi Utara. JIKMU, 5(1), hal.1-7. https://ejournal.unsrat. ac.id /index.php /jikmu /article download /7173/6684

Damanik P E G, Siregar M A, Aritonang E Y. 2014. Hubungan Status Gizi, Pemberian ASI Eksklusif, Status Imunisasi Dasar dengan Kejadian Infeksi Saluran Akut (ISPA) pada Anak Usia 12-24 Bulan Di Wilayah Kerja Puskesmas Glugur Darat Kota Medan. Jurnal Gizi, Kesehatan Reproduksi dan Epidemiologi, 1(4), hal. 1-7. https: //

\begin{tabular}{|c|c|c|c|c|c|}
\hline \multirow{3}{*}{ Variabel } & \multicolumn{4}{|c|}{ Stunting } & \multirow{3}{*}{$\begin{array}{c}\text { OR } \\
\text { CI } 95 \%\end{array}$} \\
\hline & \multicolumn{2}{|c|}{ Kasus } & \multicolumn{2}{|c|}{ Kontrol } & \\
\hline & $\mathrm{n}$ & $\%$ & $\mathrm{n}$ & $\%$ & \\
\hline \multicolumn{6}{|l|}{ ASI Eksklusif } \\
\hline Tidak Memberi & 15 & 71,4 & 22 & 34,9 & \multirow[t]{2}{*}{$\begin{array}{c}4,659 \\
(1,583-13,708)\end{array}$} \\
\hline Memberi & 6 & 28,6 & 41 & 65,1 & \\
\hline \multicolumn{6}{|c|}{ Riwayat Penyakit Infeksi } \\
\hline Menderita & 17 & 81,0 & 35 & 55,6 & \multirow[t]{2}{*}{$\begin{array}{c}3,400 \\
(1,027-11,257)\end{array}$} \\
\hline Tidak Menderita & 4 & 19,0 & 25 & 44,4 & \\
\hline \multicolumn{6}{|l|}{ Status Imunisasi } \\
\hline Tidak Lengkap & 11 & 52,4 & 14 & 22,2 & \multirow[t]{2}{*}{$\begin{array}{c}3,850 \\
(1,358-10,916)\end{array}$} \\
\hline Lengkap & 10 & 47,6 & 49 & 77,8 & \\
\hline
\end{tabular}

Tabel 1. Analisis Faktor Risiko Kejadian Stunting Pada Balita Usia 12-59 Bulan di Wilayah Tambang Poboya Kelurahan Poboya Kecamatan Mantikulore Kota Palu 
jurnal.usu.ac.id/index.php/gkre/article/view/8580

Darmadi, 2008. Infeksi Nosokomial, Jakarta: Salemba Medika.

Dinas Kesehatan Provinsi Sulawesi Tengah, 2015. Penilaian Status Gizi Provinsi Sulawesi Tengah Tahun 2015, Palu.

Fikadu, T., Assegid, S. \& Dube, L., 2014. Factors associated with stunting among children of age 24 to 59 months in Meskan district, Gurage Zone , South Ethiopia: a case-control study. BioMed Central, 14(800), hal.1-7. https://doi.org/10. 1186/1471-2458-14-800

Gibney, M., B, M. \& Kearney J, A.L., 2008. Gizi Kesehatan Masyarakat, Jakarta: EGC.

Kementrian Kesehatan RI, 2016. Situasi Balita Pendek, Jakarta.

Kementrian Kesehatan RI. 2013. Riset Kesehatan Dasar 2013. Jakarta: Kementerian Kesehatan Republik Indonesia.

Kementrian Kesehatan RI. 2015. Profil Kesehatan Indonesia tahun 2014.Jakarta: Kementian Kesehatan RI.

Picauly, I. \& Toy, S.M., 2013. Analisis Determinan Dan Pengaruh Stunting Terhadap Prestasi Belajar Anak Sekolah Di Kupang Dan Sumba Timur, NTT. Jurnal Gizi dan Pangan, 8(72), hal.55-62. https://journal.ipb.ac.id , Home , Vol 8, No 1 (2013)

Rajan, P. et al., 2012. Risk Factors for Stunting Among Children: A Community Based Case Control Study in Nepal Risk Factors for Stunting Among Children: A Community Based Case Control Study in Nepal. Kathmandu University Medical Journal, 10(39), hal.18-24. http://www.m.kumj.com np/issue/39/18-24.pdf

Stewart, C.P. et al., 2013. Contextualising complementary feeding in a broader framework for stunting prevention. Maternal and Child Nutrition, 9(2), hal.27-45.

https://escholarship.org/content/qt1g0576j2/qt1g0 576j2.pdf

Susanti G E, Tampubolon B, Agussalim. 2017. Risk Factors of the Incidence of Stunting in Senggi Public Health Center Keerom Papua 2015. Internasional Journal of Science and Research (IJSR), 6(1), hal.228-242. https://www.ijsr.net. /archive/v5i7/ART2016127.pdf

Swathma D, Lestari, H \& Ardiansyah, R, T. 2016. Analisis Faktor Risiko BBLR, Panjang Badan Bayi Saat Lahir dan Riwayat Imunisasi Dasar Terhadap Kejadian Stunting pada Balita Usia 12-36 Bulan Di Wilayah Kerja Puskesmas Kandai Kota Kendari Tahun 2016. Jurnal Ilmiah Mahasiswa Kesehatan Masyarakat, 1(3), hal.1-10. https://media.neliti.com/media/publications/18629 4-ID- analisis -faktor-risiko-bblr-panjangbada.pdf

UNSCN, 2008. 6 th Report on The World Nutrition Situation.

Wahdah, S., Jufrie, M. \& Emy, H., 2015. Faktor risiko kejadian stunting pada anak umur 6-36 bulan di wilayah pedalaman Kecamatan Silat Hulu, Kapuas Hulu, Kalimantan Barat. , 2(1), hal.2334. http://ejournal.almaata.ac.id/index.php/IJND/artic le/ view /324 